\begin{tabular}{|c|c|c|c|c|}
\hline Lupus anticoagulant & 3 & 37 & 85 & $\begin{array}{c}\text { OR: } 3.66 \\
(0.98 \\
13.72)\end{array}$ \\
\hline P-selectin & 2 & 33 & 75 & $\begin{array}{c}\text { MD: } 0.85 \\
(-0.08 \\
1.77)\end{array}$ \\
\hline Thrombomodulin & 5 & 92 & 264 & $\begin{array}{c}\text { MD: }-0.22 \\
(-0.86 \\
0.41)\end{array}$ \\
\hline $\begin{array}{l}\text { Erythrocyte } \\
\text { aggregation }\end{array}$ & 3 & 47 & 112 & $\begin{array}{c}\text { MD: }-0.24 \\
(-0.62 \\
0.15)\end{array}$ \\
\hline
\end{tabular}

MD: mean difference, OR: odds ratio, tPA: tissue plasminogen activator Disclosure of Interests: : Gul Guzelant Ozkose: None declared, Berna Yurttas: None declared, Sinem Nihal Esatoglu: None declared, Vedat Hamuryudan Consultant for: Abbvie, Amgen, BMS, Jansen, MSD, Pfizer, UCB, Speakers bureau: Abbvie, Amgen, BMS, Jansen, MSD, Pfizer, UCB, Hasan Yazici: None declared, Gulen Hatemi Consultant for: Abbvie, Amgen, BMS, Janssen, MSD, Pfizer, UCB, Speakers bureau: Abbvie, Amgen, BMS, Jansen, MSD, Pfizer, UCB,

[1] DOI: 10.1136/annrheumdis-2019-eular.7984

\section{THU0576 PROGNOSTIC FACTORS PREDICTING THE SURVIVAL OF PATIENTS WITH MACROPHAGE ACTIVATION SYNDROME}

Seungmin Jung, Sungsoo Ahn, Sangwon Lee, Jason Jungsik Song, Yongbeom Park. Yonsei University College of Medicine, Internal Medicine, Seoul, Korea, Rep. of (South Korea)

Background: Macrophage activation syndrome (MAS) is a hyperinflammatory condition, which can lead to death in patients with rheumatologic disease. However, the prognosis of adult patients with MAS is largely unknown.

Objectives: We aimed to investigate the mortality in patients with MAS accompanied Adult-onset Still's disease (AOSD) or systemic lupus erythematosus (SLE) and to evaluate the prognostic factors predicting the mortality in patients with MAS.

Methods: We retrospectively reviewed febrile patients with AOSD or SLE admitted to Severance Hospital between 2005 and 2018. Patients who satisfied the classification criteria of MAS was included in the analysis. Cox-regression analysis was performed to evaluate the clinical factors associated with the overall mortality in patients with MAS.

Results: Of the total 123 patients, 48 (39\%) patients and 75 (61\%) patients were diagnosed with AOSD and SLE, respectively. Forty-three patients (35\%) were died from MAS during hospitalization. There was no significant difference in mortality between AOSD and SLE $(P=0.675)$. In multivariate analysis, cytopenia, and insufficient reduction of ferritin and rebound of inflammation after initial treatment with glucocorticoid were independently associated with death in patients with MAS $(P=0.019$, < 0.001 , and 0.011 , respectively).

Conclusion: The presence of cytopenia, and treatment response after glucocorticoid treatment was closely related with death in patients with MAS. More intensive treatment should be considered in high-risk patients with poor prognostic factors.

\section{REFERENCES:}

[1] Carter, S.J., R.S. Tattersall, and A.V. Ramanan, Macrophage activation syndrome in adults: recent advances in pathophysiology, diagnosis and treatment. Rheumatology (Oxford), 2018.

[2] Grom, A.A., A. Horne, and F. De Benedetti, Macrophage activation syndrome in the era of biologic therapy. Nat Rev Rheumatol, 2016. 12(5): p. 259-68.

[3] Ahn, S.S., et al., Application of the 2016 EULAR/ACR/PRINTO Classification Criteria for Macrophage Activation Syndrome in Patients with Adultonset Still Disease. J Rheumatol, 2017. 44(7): p. 996-1003.

[4] Ahn, S.S., et al., In-hospital mortality in febrile lupus patients based on 2016 EULAR/ACR/PRINTO classification criteria for macrophage activation syndrome. Semin Arthritis Rheum, 2017. 47(2): p. 216-221.

Disclosure of Interests: None declared

DOI: 10.1136/annrheumdis-2019-eular.7109

\section{THU0577 EFFICACY OF RADIOSYNOVIORTHESIS IN PIGMENTED VILLONODULAR SYNOVITIS OF THE KNEE}

Zsolt Karoly Mangel, György Nagy, Margit Szentesi. Polyclinic of the Hospitaller Brothers of St. John of God, Rheumatology, Budapest, Hungary

Background: Pigmented villonodular synovitis (PVNS) is a rare disorder with the benign tumoral proliferation of the synovium. The surgical treatment of PVNS alone in most cases is unsatisfactory, because if a few cells have not been removed, the disease will recur. ${ }^{1}$ Post-synovectomy adjuvant treatment with intra-articular injection of $\mathrm{Yttrium}-90\left({ }^{90} \mathrm{Y}\right)$ or $\mathrm{Hol}$ mium-166 $\left({ }^{166} \mathrm{Ho}\right)$ yielded better results. The radiosynoviorthesis (RSO) is an effective way of treating the chronic synovitis, with this method we are eliminate the inflammation in 75 percent of the cases. ${ }^{2}$

Objectives: To study efficacy of radiosynoviorthesis after the surgical synovectomy in pigmented villonodular synovitis of the knee.

Methods: Between May 1986 and August 2018, 17 patients (seven men and ten women aged 14-68 years) with diffuse PVNS were treated. Al patients had monoarticular arthritis of the knee with histologically proved PVNS. The patients underwent 33 operations, two patients had four surgical procedures, one patient underwent three surgeries, eight patients had two surgeries and six patients had one surgical procedure (Table 1.). The radiosynoviorthesis was performed according to the method accepted in the national protocol.Yttrium-citrate injectable suspension marked by $185 \mathrm{MBq} 90 \mathrm{Y}$-citrate injectable suspension, and $40 \mathrm{mg}$ of 1 $\mathrm{ml}$ triamcinolone acetonide and $1 \mathrm{ml}$ of lidocaine $1 \%{ }^{3}$ Holmium-phytate injectable suspension marked by $600 \mathrm{MBq} 166 \mathrm{Ho}$-phytate injectable sus pension, and $40 \mathrm{mg}$ of $1 \mathrm{ml}$ triamcinolone acetonide and $1 \mathrm{ml}$ of lidocaine $1 \%{ }^{3}$

Evaulation was based on the criteria as described by Müller, Rau and Schütte the score system was developed by the authors. ${ }^{4}$ The circumference of joint-swelling, the joint function, the measure of flexio-contracture, pain in state of rest and load on a pain analogue scale 1-10, joint warmth, walking capacity, the numbers of joint-punctions after the treatment, whether operation was necessary or not after the treatment were examined.

\begin{tabular}{|c|c|c|c|c|c|c|c|}
\hline $\begin{array}{l}\text { Number of } \\
\text { patients }\end{array}$ & age & & surgery & fore RSO & & $\begin{array}{r}\text { numb } \\
\text { RS }\end{array}$ & $\begin{array}{l}\text { er of } \\
0\end{array}$ \\
\hline 7 men and & $14-68$ & 1 & 2 & 3 & 4 & 1 & 23 \\
\hline $\begin{array}{l}10 \text { women total: } \\
17\end{array}$ & years & & & & & & \\
\hline 6 patients & 8 patients & $\begin{array}{c}1 \\
\text { patient }\end{array}$ & $\begin{array}{c}2 \\
\text { patients }\end{array}$ & $\begin{array}{c}10 \\
\text { patients }\end{array}$ & $\begin{array}{c}6 \\
\text { patients }\end{array}$ & $\begin{array}{c}1 \\
\text { patient }\end{array}$ & \\
\hline
\end{tabular}

Table 1. Patients with pigmented villonodular synovitis

Results: Mean follow-up time was 56 months (range from 4 to 144 months). All patients were followed up using clinical assesment. After the first injection excellent and good results were recorded in $41 \%$. After the second radiosynoviorthesis thirteen patients (76\%) showed excellent and good response (Table 2.). The mean functional evaluation score of 17 patients was 28 (range 16-34). Most of the ratings were excellent or good, in four cases moderate $(24 \%)$. No complications were noticed after surgery or after the radiosynoviorthesis.

\begin{tabular}{lccc}
\hline $\begin{array}{l}\text { functional evaluation } \\
\text { score }\end{array}$ & response & patients & $\%$ \\
\hline $29-35$ & excellent & 10 & $59 \%$ \\
$22-28$ & good & 3 & $18 \%$ \\
$15-21$ & moderate & 4 & $23 \%$ \\
$8-14$ & mild & 0 & \\
$0-7$ & worsening & 0 & \\
\hline
\end{tabular}

Table 2. Functional evaluation score after the RSO

Conclusion: A combination of debulking surgery with radiosynoviorthesis of Yttrium or Holmium for diffuse PVNS of the knee joint is a reliable treatment method, with good results.

\section{REFERENCES :}

[1] Jaffe HL, Lichtenstein L, Sutro CJ (1941) Pigmented villonodular synovitis: bursitis and tenosynovitis. Arch Pathol. 31:731-765.

[2] Jahangier ZN, Moolenburgh JD, Jacobs JWG, et al. The effect of radiation synovectomy in patients with persistent arthritis: A prospective study. Clin. and Exp. Rheumatol. 2001; 19:417-424.

[3] EANM Procedure Guidelines for Radiosynovectomy, Eur J Nucl Med (2003) 30:BP12-BP16, Vol. 30, No. 3, March 2003. 
[4] Rau R, Schütte H. Results of radiosynoviorthesis with yttrium 90 in chronic synovitis: a long-term prospective study. I. Total results and effect of local factors. Z Rheumatol. 1983; 42: 265-70.

Disclosure of Interests: None declared

DOI: 10.1136/annrheumdis-2019-eular.2843

\section{THU0578 COMMON VARIABLE INMUNODEFICIENCY IN PATIENTS WITH SARCOIDOSIS}

Isabel Madroñal García, Clara Aguilera Cros, Maria Dolores Arcila Duran, Lara Mendez, Marina Gomez Vargas, Alberto Ruiz Roman, Noemi Patricia Garrido Puñal, Ricardo Juan Gil Velez, Jose Antonio Rodriguez Portal, Esteban Rubio Romero. Hospital Universitario Virgen del Rocío, Reumatologia, Sevilla, Spain

Background: Common variable immunodeficiency (CVID) is a primary immunodeficiency characterized by hypogammaglobulinemia and a deficient production of specific antibodies. Almost $30 \%$ of patients with CVID develop an autoinmmune and granulomatous disease, similar to clinical and histological sarcoidosis (S), it affects the lung fundamentally. This can lead to a misdiagnosis of $S$ in a patient with CVID, this leads to inadequate treatment and increases the morbidity and mortality of the disease.

Objectives: Describe the clinical and radiological characteristics of a cohort of patients diagnosed with $S$ with predominant pulmonary involvent. Make a study of immunoglobulin (IG) levels to see the frequency of CVID in these patients.

Methods: Retrospective descriptive study of patients treated in our Hospital (2008-2018), with diagnosis of S. The data was obtained by reviewing medical records. The delay in the diagnosis of $S$ was defined as the difference in months between the initial diagnostic suspicion and the final diagnosis of $\mathrm{S}$.

In patients with low levels IG, we have done and expanded ID study.

Results: 55 patients (31 women) were included, with a mean age of 52 \pm 12 years. The initial diagnosis was: $85 \% \mathrm{~S}, 10 \%$ lymphoma and $4 \%$ tuberculosis. The median of months from the start of the clinic to the diagnosis of $\mathrm{S}$ was 5.5 months.

Regarding the clinic, $21 \%$ patients present fever at the beginning of the disease, and $65 \%$ extrathoracic localization (cutaneous was the most frequent in $27 \%$, and renal was the least frequent $5 \%$ ). Simple $x$-ray and high resolution tomography of chest were done in all patients. Pulmonary stage 2 was the most frequent $(51 \%)$, followed by stage $3(16 \%)$, stage $0(14 \%)$ and stage $4(9 \%)$.

In $90 \%$ of the patients, histological confirmation was obtained by transbronchial $(47 \%)$, cutaneous $(11 \%)$ or lymph node biopsy $(29 \%)$.

Igs were normal in $87 \%$ of patients, only 4 patients had low IG levels ( Ig $G$ in 3 patients and $\lg M$ in 1). An extended ID study was performed in these 4 patients, being diagnosed with CVID 3 patients.

Results of the 4 patients and the differential characteristics between CVID and $S$ in table 1.

\begin{tabular}{|c|c|c|c|c|c|c|}
\hline $\begin{array}{l}\text { Differential } \\
\text { diagnosis }\end{array}$ & CVID & Sarcoidosis & Patient 1 & Patient 2 & Patient 3 & Patient 4 \\
\hline $\begin{array}{l}\text { Recurrent } \\
\text { infections }\end{array}$ & +++ & $+/-$ & Yes & Yes & Yes & Yes \\
\hline Autoimmunity & +++ & + & Yes & Yes & No & No \\
\hline Splenomegaly & +++ & $+/-$ & Yes & Yes & Yes & Yes \\
\hline Hepatomegaly & +++ & $+/-$ & Yes & Yes & Yes & Yes \\
\hline Low levels IG & +++ & $+/-$ & Yes & Yes & Yes & $\begin{array}{c}\text { Low levels } \\
\text { lgM }\end{array}$ \\
\hline Clinic & & & Pulmonary & Pulmonary & Pulmonary & Pulmonary \\
\hline $\begin{array}{l}\text { Radiological } \\
\text { stage }\end{array}$ & & & Stage 2 & Stage 2 & Stage 2 & Stage 2 \\
\hline $\begin{array}{l}\text { Histological } \\
\text { granuloma }\end{array}$ & +++ & +++ & Yes & Yes & Yes & Yes \\
\hline $\begin{array}{l}\text { Increase of } \\
C D 4 / C D 8 \text { in } \\
\text { BAL }\end{array}$ & + & +++ & Low levels & Low levels & Low levels & Not done \\
\hline Treatment & & & Corticoids & Corticoids & Corticoids & Corticoids \\
\hline
\end{tabular}

Conclusion: Although their clinical presentation and histological appearance may be identical, the management of these two conditions is very different. The difficulties in the differential diagnosis between $S$ and CVID, shows the importance of a history of screening for recurrent infections and the measurement of IG levels before the diagnosis of possible $S$.

Disclosure of Interests: None declared

DOI: 10.1136/annrheumdis-2019-eular.6339

\section{THU0579}

CHEMOKINE AND CYTOKINE TEARS PROFILE OF PATIENTS WITH IGG4-RELATED DISEASE

Eduardo Martin-Nares, Luis Llorente, Isela Chan-Campos, Diego HernándezRamírez, Guadalupe Lima, Vanessa Saavedra-González, Gabriela HernandezMolina. Instituto Nacional de Ciencias Médicas y Nutrición Salvador Zubirán, Immunology and Rheumatology, Mexico City, Mexico

Background: The lacrimal gland is frequently involved in both lgG4 related disease (IgG4-RD) and Sjögren's syndrome (SS) and presents with swelling and/or dry eye symptoms. Although a distinct chemokine and cytokine tear profile might distinguish SS from idiopathic dry eye, as of today no study has assessed this issue in IgG4-RD.

Objectives: To evaluate and compare a set of chemokine/cytokine in the tears of patients with IgG4-RD and primary SS.

Methods: We included 11 patients with IgG4-RD according to the Com prehensive Diagnostic Criteria for IgG4-RD and 17 with primary SS according the AECG criteria, who attended a tertiary referral center in Mexico City. Schirmer-I test were performed using two standardized sterile tear strips, and then immediately frozen at $-86^{\circ} \mathrm{C}$ until assayed. Once defrosted, the tears were extracted from the strips using a buffer containing $0.5 \mathrm{M} \mathrm{NaCl}$ and $0.5 \%$ Tween-20. Then, the amount $(\mathrm{pg} / \mathrm{mL})$ of the following selected chemokines and cytokines were measured by Luminometry: CCL11, G-CSF, IFN- $\gamma$, IL-12p40, IL-12p70, IL-13, IL-17A, IL-1 $\alpha$, IL$1 \beta$, IL-4, IL-7, CXCL10, CCL2, CCL3, CCL4 and TNF- $\alpha$.

Results: Patients with IgG4-RD were younger $(51.3 \pm 14.7$ vs. $55.7 \pm 10.6)$ and more frequently men $(45.5 \%$ vs. $5.9 \%)$ than SS patients. Regarding the IgG4-RD group, $7(63.6 \%)$ had lacrimal gland involvement, $5(45.5 \%)$ dry eye symptoms and $6(54.5 \%)$ positive Schirmer-I test. We observed multi-organic involvement in 9 patients $(81.8 \%)$, median number of involved organs of $5,9(81.8 \%)$ patients had active disease, median IgG4-RD responder index of 6 points, $8(72.7 \%)$ patients had high IgG4 serum levels, and $9(81.8 \%)$ biopsy proven diagnosis. We found higher levels of IL-7 and CCL2, and a trend for G-CSF in the IgG4-RD group. Conversely, primary SS patients had higher levels of IL-12p40, IL-1 $\alpha$, IL$1 \beta$, CCL3 and CCL4. At the logistic regression analysis, the variables that remained associated with IgG4-RD were IL-7 (OR $1.4395 \% \mathrm{Cl}$ 1.06-1.93, $\mathrm{p}=0.01$ ) and IL12p40 (OR 0.92, 95\% Cl 0.84-0.99, $\mathrm{p}=0.01$ ).

In a sensitivity analysis, including only 7 IgG4-RD patients with dacryoadenitis, we also observed higher levels of IL-7 and G-CSF in the IgG4$\mathrm{RD}$ group vs primary SS.

Conclusion: The chemokine and cytokine profile of tears of patients with IgG4-RD is characterized by a mixed immune response (Th1/Th2/Th17) compare with a predominantly Th1 response in primary SS. Our results also suggest a possible role of IL-7 in the pathogenesis of IgG4-RD.

\section{REFERENCES}

[1] Hernández-Ruiz M, Zlotnik A, Llorente L, Hernandez-Molina G. Markedly high salivary and lacrimal CXCL17 levels in primary Sjögren's syndrome. Joint Bone Spine. 2018 May;85(3):379-380.

Table 1:

\begin{tabular}{lccc}
\hline $\begin{array}{l}\text { Chemokine/cytokine pg/mL, median } \\
\text { (range) }\end{array}$ & IgG4-RD $\mathrm{n}=\mathbf{1 1}$ & $\mathrm{pSS} \mathrm{n}=\mathbf{1 7}$ & $\boldsymbol{p}$ \\
\hline CCL11 & $11.9(3.7-34.4)$ & $15.4(3.7-33.0)$ & 0.06 \\
G-CSF & $118.7(14.5-325.9)$ & $88.5(14.5-226.5)$ & 0.08 \\
IFN- - & $1.3(0.3-2.1)$ & $1.7(0.01-7.2)$ & 0.19 \\
IL-12p40 & $8.7(1.3-35.5)$ & $24.1(1.3-69.3)$ & 0.02 \\
IL-12p70 & $0.5(0.09-3.1)$ & $1.6(0.09-28.1)$ & 0.05 \\
IL-13 & $19.2(4.6-84.9)$ & $18.1(2.4-75.0)$ & 0.30 \\
IL-17A & $0.9(0.2-1.7)$ & $0.9(0.08-4.9)$ & 0.89 \\
IL-1 $\alpha$ & $25.8(10.5-166.8)$ & $54.3(21.6-119.1)$ & 0.003 \\
IL-1 $\beta$ & $0.1(0.1-1.5)$ & $1.5(0.1-7.2)$ & 0.001 \\
IL-4 & $11.0(1.8-17.6)$ & $8.2(1.8-19.8)$ & 0.45 \\
IL-7 & $13.8(6.6-65.1)$ & $6.4(1.27-15.0)$ & 0.001 \\
CXCL10 & $5399.5(296.9-$ & $5368.1(1205-$ & 0.51 \\
& $11394)$ & $11553.6)$ & \\
CCL2 & $11.4(1.1-104.4)$ & $1.1(1.1-166.3)$ & 0.03 \\
CCL3 & $2.4(0.3-4.0)$ & $3.4(1.1-40.7)$ & 0.01 \\
CCL4 & $1.2(1.2-27.6)$ & $11.1(1.2-164.3)$ & 0.02 \\
TNF- $\alpha$ & $0.8(0.1-5.4)$ & $2.03(0.1-7.6)$ & 0.06 \\
\hline
\end{tabular}

Disclosure of Interests: None declared DOI: 10.1136/annrheumdis-2019-eular.4183 